\title{
Societal Insecurities in Western Balkans. A Case Study on Macedonia
}

\author{
Granit Zela
}

\author{
PhD Candidate, Armed Forces Academy, Tirana-Albania
}

\section{Doi:10.5901/mjss.2013.v4n13p407}

\section{Abstract}

Societal security is particularly efficient as an analytical tool to understand the security concerns of "multiethnic states", the relationship between the country's regime (the majority group) and the minority groups. During the dissolution of Yugoslavia, nationalism, disintegration, ethnic identity were the main security issues in the Western Balkans in the last decade of the twentieth century and the first decade of the twentieth century. In this paper, the relationship between the Macedonian and Albanian population in Macedonia is considered in the perspective of the social insecurity established after the creation of the independent Macedonian state as a "national state" of the ethnic Macedonian majority and not a "citizen-state" of all ethnicities and identities as well as in the perspective of linguistic disparity between Macedonians and Albanians, both cases constituting two application instances of this analytical approach.

Keywords: Societal security, Western Balkans, Macedonia, national identity, linguistic equality, national-state, civic state.

\section{Introduction}

The different state legacies of regional security complexes with its emphasis on the global and regional levels, makes it easy to slip into the assumption that the world has evolved The world has evolved into a fairly uniform system of Westphalian-type states differentiated from each other principally by their degree of power, their geographical location, and their cultural background. But it is all too clear that the state level itself contains variables that play a major role in conditioning the how and why of security dynamics in any given region.(Buzan,Weaver 2003:20)This spectrum of states is not just about power but also the degree of socio-political cohesion between civic society and governing institutions. In other words, it is related to the degree of "citizenship" in the sense of "empirical sovereignty" that a country possesses.

"Weak states" ensure favorable conditions to study societal insecurity and the security studies literature has started to make use of it. Societal security is a term that was frequently used in Eastern Europe during the breakup of the former Yugoslavia, as an analytical instrument of its constituent conflicting societies in the then-Yugoslav state and afterwards. In this region and elsewhere, societal security referred to sustainable development of traditional patterns of language, culture, religion and national identities and traditions of countries (Collins 2011:215).

This term extended the security concept by discussing about the security of collectivities and "societies" as an approach in between the "human security" and "global security". Societal security, which was previously one of the national security dimensions, became a separate referent object of security, whose concerns were related to threats and risks posed to the identity of society, the survival of its identity as survival of the society itself.

\section{Western Balkans' states as study object of societal security}

Historians have tried to explain the crisis of the Balkan states as a result of delayed and incomplete process of statebuilding, processes that are typical in the political developments of the late 19th and in the early 20th century. According to this view, state weakness is characteristic of this region and it originates from are: impact of abandoning the political isolation, introduction of constitutional elections and the influence of the dominant project of post-communist elites. (Collins 2011:233)

Given this analytical framework, it is logical to say that such a region as Western Balkans, composed of weak states, develops security dynamics that would be entirely different if the region would consist of strong states, while this analytical framework should take into account the history of the (in)security of this (sub) region. In Western Balkans transition consisted of state-building, building a credible and legitimate state for the citizens, who consider the state as corruptible and inefficient. The region now represents a mixture of weak states, failed states former failed states and states that are almost sovereign states having a protectorate dimension. 
After the period of the disintegration of Yugoslavia, nationalism, disintegration, ethnic identity were the main security issues in the Western Balkans during the last decade of the twentieth century and the first decade of the twenty first century. Albania, the same as Germany, Hungary, Russia and to some extent Serbia, is a country that is shrunk in a narrower space than it's ethnic space. There is an Albanian minority in Serbia, Macedonia Montenegro (approximately $40 \%$ of the population), and in Greece.(Buzan, Weaver 2003:38)

Societal security is crucial to the issues related to the national identity of these Albanian populations, since thes eissues have appeared time and again the center of clashes and axis of fears. The whole region is composed of a multiplicity of issues that are in the central hearth of societal, political and ethno-territorial conflicts; coexistence of three different ethnicities in Bosnia or their division; mutual concerns about the respective minorities in Albania and Greece; different interpretations of Macedonian statehood by the Serbs, Bulgarians, Albanians and Greeks, the position of Serbs in Mitrovica as well as position of Albanians in southern Serbia, etc.

\section{National state of Macedonia 1991-2001, as a societal security dilemma}

If a society loses its identity, it will not survive anymore as a society. States may become unsafe due to threats posed to their societies. But national security can be questioned also due to a high level of social cohesion. This refers to instances when a state program of homogenization is conflicting with a strong identity of one or more of its minority groups. For instance, during the 90s, "Romanism"of the Romanian state was compromised, while the large Hungarian minority in Transylvania region strengthened the "hungarism".(Collins 2011:220) Alan Collins explores this conflict in his discussion of social security dilemmas. In other words, according to Collins, the safer these societies become, in terms of social security, the less sure can feel their states. The same thing happened with the Macedonian state after independence, the pursuit of a strong policy of "macedonism" of the society and homogeonize the Albanian populations suppressed and expression of the Albanian identity, causing the reaction of the Albanian population which felt an existential threat in terms of its own identity.

Threats toward social security exist when a society perceives that its collective identity is called into question. This was the perception that the Albanian population had in Macedonia after the adoption of the Constitution in 1991. Instruments that can provide societal insecurity can range from suppression of expressing the identity to intervening in the ability of the insecure society to reproduce through generations. According to Buzan this may include banning the use of language, names, traditional clothing, to the banning of education of these societal groups. Threats to the reproduction of the society can be done through the methodical application of repressive measures against identity expression.(Collins 2011:222) The path towards the Macedonian "national state" was faced with the dilemma of societal security of this country that in 1991 chose to become a "national state" of only one ethnicity by supporting and sanctioning by the Constitution the Macedonian ethnic dominance as an expression of the very concept of the "national state" having a cultural dominance of one ethnicity towards other ethnicities.

\subsection{Language as a dimension of the internal geopolitics in Macedonia}

Since the beginning of its use, up to the present, besides the communication role which can be considered a technical function, language has had the social, cultural, civilization and scientific nature as well. In this case, it should be noted, that language, as one of the identifying elements, and the most important among them, became an integral part of national identities. It is also an expression of cultural and historical traditions, according to which we learn about the antiquity of the nation, its development and the challenges along the its life road, from the very earliest times until today.

In different periods of captivity by many rulers, Albanian language was banned, underestimated and threatened by a fatal annihilation. Despite these ongoing assimilating trends, it managed to survive and today is used by all Albanians, wherever they live. At present, this language, except the official use in Albania and in the new state of Kosovo, where the Serbian language is guaranteed by having an official status, it is also used by many other ethnic Albanian speaking populations in their territories, within the different Western Balkans countries, par of which is Macedonia. The status of the Albanian language in Macedonia, in the country where it is spoken by $30 \%$ (officially $25 \%$ ) of the population, it seems to have the same fate of those who speak it, because linguistic pluralism in this country was understood and interpreted according to the will of the people constituting the majority and their political elite which sanctioned it's position by different laws that favored only the language of the Macedonian majority. This concept of the state brought about linguistic inequality and unequal status of the Albanian language as a fundamental instrument of expression of the identity of the Albanian population. (Bexheti 2011) 
The "national Macedonian state" shaped by the Constitution of 1991, ignored the linguistic status of speaking communities in the Republic of Macedonia as a vital factor of a country's domestic geopolitics by imposing the linguistic dominance of a single ethnic group against the other language communities, respectively toward the Albanian language. If we refer to the fact that social and state entities are usually multilingual entities, even in cases where linguistic minorities are in small numbers, it is quite clear that determining the status of languages is a significant activity, but very important for those entities also in the case of Macedonia, the status of the Albanian language constitutes an indication of social status that the Albanian population has in Macedonia. Being a factor internal geopolitics of the states, in the case of deep linguistic inequality of the status of a language community, language becomes a factor of social insecurity of the ethnic group that speaks it.

One of the serious problems that affected the escalation if the Albanian-Macedonian dispute into an armed conflict is that one dealing with the requirements for the progress of language, respectively it's formalization as an equal language in the Republic of Macedonia. After adoption of the Constitution of the Republic of Macedonia of 1991 without the votes of Albanian deputies, Albanians, as the second population in number after the population of Macedonians, did not gain legal rights as as an equal language community with Macedonians.

The Constitution of 1991 was much more restrictive in terms of the use of the Albanian language as an official language. It did not guarantee even what was the legacy of the Albanians by Yugoslav Constitution of 1974, where the Albanian language enjoyed widespread use in several areas of public life (in administration, civil procedure, criminal code procedures, etc.) even though the provisions of this Constitution were never fully implemented in public and social life in the former Socialist Republic of Macedonia and the former Yugoslavia.(Zeneli 2003:163) The laws, which were adopted later, according to the constitution of 1991, as the Law on Public Administration, Law on criminal procedure, civil procedure, as well as many other laws which regulated the issue of the official use of the Albanian language in the important areas of public life, the Albanian language was completely and utterly marginalized, and almost was positioned only for private use.

According to the Constitution of the Republic of Macedonia 1991', Article 7, Section 1, "In the Republic of Macedonia, the official language is the Macedonian language and the Cyrillic alphabet". While, in the local administrative self-governance units, where the majority consists of members belonging other nationalities, despite the Macedonian language and Cyrillic alphabet, it is also used the language and writing of nationalities in majority according to the law. Based on the solutions offered by Article 7 of the Constitution of the Republic of Macedonia, the official use of the Albanian language is categorized in: the use of the Albanian language in local self-governance where the majority conists of Albanians, the use of the Albanian language in local self-governance administrative units where Albanians consitute a significant number and use of Albanian language in the municipalities where the Albanian language is not used as an official language.

The solutions provided in the Constitution of the Republic of Macedonia, the official use of the Albanian language is limited to the use of languages in the local self-administration bodies, but taking into account that the state power in the Republic of Macedonia is very centralized, then one can't think of equality of languages in the legal system of the Republic of Macedonia. The Constitution of Macedonia in 1991, with solutions that made in terms of the dimension of the use of Albanian language as an official language, was below the level foreseen in the European Charter for Regional or Minority Languages of the Council of Europe, November 1992.

\subsection{Linguistic equality in Macedonia as a security dilemma of "civic state" after 2001}

Such a discriminatory position of the Albanian language and the Albanians that are today the largest community after the Macedonians in Macedonia, brought about the inter-ethnic conflict for equality and greater rights which was ended by the international intervention that was finalized with the Ohrid Framework Agreement, signed on August 13, 2001. Based on the obligations deriving from the Ohrid Framework Agreement, the Republican Assembly approved on November 16,

\footnotetext{
${ }^{1}$ Republic of Macedonia was constituted as a sovereign and independent state based on the Declaration for the Sovereignity of the Socialist Republic of Macedonia of 1991 and on the basis of the plebicitary will of the citizens of the Republic of Macedonia expressed in the referendum held on september 1991 which opened the process of the independence of the Republic of Macedonia as an independent and sovereign state. On November 17, 1991, was approved the Constitution of the Republic of Macedonia and was constituted the political and legal basis for the creation of the new state. The albanian population boycotted the referendum for independence while the albanian deputies boycotted the approval of the new Constitution. The motive of boycot was the fact that the requests of the Albanians for an equal juridiscal-constitutional status were rejected and according to the new changes of 1991 , their rights were below the level of the Constitution of 1974.
} 
2001 the constitutional amendments and the preamble to the new Constitution. Use of language was sanctioned by Amendment $\mathrm{V}$, an Amendment in which prevails the spirit of the Ohrid document.

In the constitutional-legal perspective, the Ohrid Agreement presents an inevitable compromise on the rights and freedoms of ethnic communities in the Republic of Macedonia. The Framework Agreement places the citizen at the center of political and constitutional system, meeting all the wills of each individual separately and their collectivities together to achieve peace, democracy, progress and overall harmony. In the text of the Framework Agreement itself it is stated that "This Framework Agreement will promote the peaceful and harmonious development of civic society, by simultaneously respecting the ethnic identity and interests of all Macedonian citizens."

Ohrid Framework Agreement contains the preservation of multi-ethnic character of the Macedonian society in public life, non-discrimination and equitable representation, Special Parliamentary procedures that imply that enacting laws that directly affect culture, use of language, education personal documents, the use of symbols and the use of language education, related with: providing financial support for the Higher Education by the state in the languages spoken by at least $20 \%$ of the population, on the basis of specific agreements it is necessary to have the consent of that community. In the entire territory of Macedonia and in international relations, the official language is the Macedonian language, while below it is provided that "any other language spoken by $20 \%$ of the population is also an official language ...."; In the part related to the expression of identity, it is implied that next to the symbol of the Republic of Macedonia, local authorities will be free to put in the local public buildings the emblems representing the identity of the community which constitutes the majority in the municipality.

In multilingual communities, due to the impact of extra-lingual factors and due to the political, economic and cultural advantages of specific speaking communities towards other speaking communities of that entity, are created attitudes that are sociologically and ideologically motivated between speakers of different languages. Defining the status of languages is intended to regulate these relationships and attitudes and legally define the use of different languages in different domains and functions. (Munishi 2009) Equal use of the Albanian language in the central government and particularly in the highest legislative body is a permanent requirement of the Albanian political factor since the independence of the Republic of Macedonia. According to the Regulation of the Assembly of the Republic of Macedonia, Article 3 "MP who speaks a language other than the Macedonian language, languages spoken by at least $20 \%$ of the citizens of the Republic of Macedonia, may speak that language at the Assembly meetings and the Assembly working bodies.

If the breakup of Yugoslavia occurred, inter alia, as a result of discrimination of many languages, besides Serbian language, formally called "Serb-Croat language", then the question is how can a new pluralistic democratic state that emerged from the dissolution of the federation, because of the dominance of the largest population and the violation of other peoples' rights, with particular emphasis on minimizing their languages and banning or restriction of use in the institutions of central government, again, having experienced that, after the dissolution there was only one official language, the Macedonian language.

Recycling the phenomenon of the privileged language, the language of the Macedonian majority and the depreciation of other languages, especially the Albanian language, which is used by the second largest population in size after the Macedonians, damages essentially the multilingual, multiethnic Macedonian state itself. Linguistic pluralism, as the value and treasure that ennobles the common life of peoples within a state, mutual linguistic, cultural respect and the respect of other characteristics that distinguish peoples form each other. This ideology of linguistic pluralism, implies recognizing more languages according to the territorial principle. Linguistic pluralism, according to experts in this field can be complete or partial, may involve all aspects of life, or only some of them in one more languages.

Albanian language in Macedonia, at all stages of the development of statehood, including the time period when RM was part of federal Yugoslavia, including the time period after the independence of interethnic pre-conflict and that of the conflict period which ended with an agreement that was the main goal of the conflict, did not gain a sustainable official status. Even with the Ohrid Agreement reached in 2001, whose implementation was guaranteed by the international community, did not gain those national rights and neither did they gain the official language status, while in some segments, their position marked a drawback (pedagogical documentation in the former Yugoslavia, for Albanians was written only in Albanian, but now, after this Agreement, this documentation must be in Macedonian language as well). In this arrangement, at first glance, there seems a progress of the Albanian language, but in no way there is not any equality with the Macedonian language, which in this document, not only kept it's privileged language position, but in comparison with the Constitution of 1974, was advanced at the level of the only main official language. This language status of the majority population, was already a position guaranteed the Constitution of 1991.

The Ohrid Agreement includes the issue of language usage in Section 6, entitled: Education and Use of 
Languages. In paragraph 2 of this article, which is about the right to use languages in higher education, Albanian language is not mentioned at all, but is is only implied by the percentage, as it can also be implied other languages that do not belong to the majority population. This paragraph of Article 6 , is formulated as follows: State funding will be provided for higher education in the languages spoken by at least $20 \%$ of the population in Macedonia. In this article of this important document, in which the Albanians expected progress of their language, the status of the official authentic language and equality with the Macedonians, the phrase "Albanian language" was replaced with the word "percentage", which never happened before, nor in the time of the federal state of socialist Yugoslavia.

This formulation is intended for a long time to come to the conclusion that in Macedonia there is only one official language, the Macedonian language and all other languages are second-hand languages, if they reaches the required percentage, but not equal to Macedonian language. Paragraph 4 of Article 6, defines the Macedonian as the sole official language throughout the Republic of Macedonia and in international relations. Although in paragraph 5 of this article is stated that: Any other language spoken by at least $20 \%$ of the population is also an official language, there is confusion and it seems deliberately to allow manipulations and obstacles to the proper use of this percentage which at present implies Albanians. If we make a comparison of this paragraph, with paragraph 4, which defines Macedonian langauge as the sole official language in the whole territory, we will see that in paragraph 5, are not mentioned the words: In the entire territory of Macedonia, thus opening the possibility for manipulation and dilemmas, if the language that meets the percentage may have spread use throughout the Central Governing Authority, or only to the local level. In the same paragraph of Article 6, it is stated that: any official language other than Macedonian may be used in accordance with the law. (Bexheti 2011)

In this part of the article, the second official language can be used, but it is implied that in some cases it can not be used, because if one follows a logic interpretation this is not obligatory, and there are not laws that foresee sanctions for not using the second official language, which isn't mentioned anywhere to be the Albanian language. This means that this language, is already turned into a percentage, and is used based on the private will of the individual. If we add to this the words: Regulated by law, we should taken into consideration that "Law on Use of Languages", marginalizes further the status of the Albanian language, we come to the conclusion that Article 6 of the Framework Agreement, the official status of the language at the percentage of at least $20 \%$, is more of a political nature, and does not argue the position of a so-called Second Official Language. This linguistic discrimination to the detriment of the Albanian language, is noticed also in the sections dealing with the Local Self-Government Authority. This is proved by the formulation: The language of that community (if it is at least 20\%) will be used as an official language in addition to Macedonian. Even this right, in many municipalities where $20 \%$ is reached, can not be easily exercises, if such action is not supported by the Macedonian majority, something that is argued in this part of Article 6: In relation to languages spoken by at least $20 \%$ of the population of the municipality, the local authorities in a democratic way (through voting) will decide on its use in public bodies.(Bexheti 2011)

Ohrid Framework Agreement, however, is a step forward in the advancement of the rights of Albanians in general and in particular the formalization of the Albanian language as official language in local and central governing levels. After the constitutional changes of 2001, the Albanian language in local self-government units, has a wider use compared to Law of 1995. The new law increases the powers of municipalities in other activities such as in urbanism, social policy, education, primary and secondary education, health, etc., which means that even with these activities, the use of the Albanian language as an official language will come to expression and will be applicable for the Albanian population.

There is further progress also in the use of the Albanian language in personal documents, public administration, court procedures, procedures in the Republican Judicial Council etc. All personal documents of the citizens speaking an official language different from the Macedonian language, are to be written in that language. In all these documents, names and surnames of Albanians are ritten only in Slavic language and the Cyrillic alphabet thus losing their meaning. (Zeneli 2003:169) Despite this step forward, the doubling of writing the data, starting from the a name and last name of the person, and other data, in two languages and two alphabets, the Cyrillic and the Latin-based Albanian alphabet, often causes problems in identification, because the document holder bears two names, depending on the letters used while its is foreseen also the withdrawal of the person for request (bilingual documents are issued only based on a special request) to have the personal documents issued in two languages.

The biggest problem is the the failure to implement this Agreement in the daily practical life. 2011 marked the tenth anniversary of the day the Agreement was adopted and indeed it was found that this arrangement, with all its faults, could not even be implemented, so the rights of Albanians, among which is also the use of Albanian language, even after the conflict of 2001 and the Ohrid Framework Agreement that emerged from this conflict, still is not implemented. According to the most recent developments, 43 names that coincide with important dates and significant personalities of 
the Albanian history and culture, are expected to be given to streets, squares, bridges and other infrastructure facilities in Skopje. Let us hope that the political elites of both main ethnicities activate de facto the full "geopolitical planning" arsenal in their policy based on "civic" and not "national" concept of citizenship, and in this framework, work for the language equality.

\section{Societal dilemmas between the "national" and "civic" in Western Balkans}

The difference between the Western Balkans and Central and Eastern European countries has to do with the highest degree heterogeneous population, but also the nationalist policy of almost all the leaders from the region. Balkan region represents an integral part of the new European space and at the same time it is the region less stable and less integrated in Europe. Societies of the region have difficulty to liberate themselves from the mentality of the "national" in favor of the "civic". This idea is also present to social segments of the political elites and some statesmen in Western Balkan countries who ultimately are the products of Balkan societies. Some of them are based on historical references to make these arguments acceptable.

An important direction of development in the Western Balkans jas at its foundation the development of the region through mutual respect and the mutual state, ethnic, religious, civic state equality in service of the civic state. This version is based on the platform of creating lasting active connections and good neighborly relations between the countries of the Western Balkans region, expressed in joint regional initiatives towards integration of the region into EuroAtlantic structures. Even in this case, given the current development trends in the context of domestic relations and interstate relations one poses the question: How far is the time of the model of the civic state the whole of the region?

We can say that the best solution for the Balkan societies is to allow and encourage the liberal concept of human rights in general, associated with the well-defining the constitutional and legal mechanisms that ensure the protection of individual rights, the civil rights, rights of minorities in all aspects. On the other hand, these judicial constitutional and legal mechanisms should sanction the necessary legal restrictions to all levels of government and power in order to protect civil rights regardless of ethnicity, religion, race, etc, beyond differences and ethno-cultural polarization within and between the regional societies. (Bexheti 2011)

The problem of equality of languages in Europe and their status is a problem that has evolved along with human consciousness. In this issue are reflected not only the ideological and political changes that have occurred in different social entities of the state of Europe, but also the change of mentality and culture of European peoples. This process is in constant motion in time and space. On the other hand, in Europe, in most cases there existed the practice of favoring the centralized power of the majority language. Then, it was applied the reduction of the functions performed by that power, giving greater autonomy yo local collectivities. Thus Europe was unified. This model became a tool for solving horrific problems between nationalities, while today involves numerous states. This conflict community must be addressed through an original way, where power structures must be mitigated through a confederate system, where you have to agree on a balance of nationalities efforts with the majority population. This act should be done also due to the fact that because of the disparity between the language of the majority and the minority language may compromise peace as it was the case in 2001 in Macedonia, but also in other regions of the former Yugoslavia and the former Soviet Union.

\section{Conclusions}

Societal Security is particularly efficient as an analytical tool to understand the security concerns of "multiethnic states", the relationship between the regime (the majority group) and the country's minority groups. During the nation building process, state regimes may require from minority groups to give up the entire or a part of their cultural characteristics, which leads to the assimilation of the identity of the minorities within the majority. And precisely this lack of cohesion between the state and its society defines the state as "weak". (Collins 2011:233)

If war is the continuation of politics by other means, then the language policy represents milder form of war between nations. And if once and for all nations get rid of the ideas of domination of one language over another language, then this idea could one day be the savior not only for this state, but also for a country larger and more powerful than the state of Macedonia. Based on what we stated above, the Albanian language should be an official language, which means language of power, which enables individual progress, and the individual must be considered as key to the success of a society. (Ibrahimi2033:118)

In order to create a framework for a bilingual environment, there must be reciprocity in learning the language of the other in state institutions. Clearly, this should not cause any complex and no fear of state disintegration, something that 
tends to disconnect or threaten vital interests. On the contrary, this act constitutes a greater enrichment of human heritage and adding to this we may mention what Latins used to say: a man is worth of how many languages he knows. This is because: living together with another entity, working together, creating together, making the economy together and not knowing the language of each other, could take place only in totalitarian states where it ruled the dictatorship of the proletariat, a tough form of hegemony, or occurs in countries lacking completely freedom and rights. (Hysa 2003:118)

Despite the apparent progress of the status of using the Albanian language after the Ohrid Framework Agreement, there remain numerous challenges for the Albanian language as the second official language in the Republic of Macedonia, aspiring to have an equal status with the Macedonian language, at least, as it requires the Ohrid Framework Agreement; establish full equality of languages, as a prerequisite for full ethnic equality in all spheres of public and social life which means raising the Albanian language as an equal language in the public life of the Republic of Macedonia.

Preservation and promotion of cultural and linguistic diversity in the Western Balkan countries and especially in Macedonia, it was not perceived as one of the standards that must be met in the process of European integration. This approach should be added to the nationalist linguistic policies that are followed by the Balkan states during the XIX and $X X$ centuries. Legal solutions that have been made in the field of language status can be regarded as incomplete solutions in the region. Institutional approach to the problem of equality of languages can be considered quite weak in relation to language policies pursued in European countries. In the field of language policy and access to linguistic equality, Macedonia should work further to enhance language equality standards, which at the current level are perceived as a threat and societal insecurity and dilemma for the Albanian population.

\section{References}

Buzan Barry, Weaver Oele, Regions and Powers: The Structure of International Security. Cambridge University Press. 2003.

Bexheti Vebi, The status of the Albanian language in Macedonia after the Ohrid Agreement, Newspaper Koha, 20/08/2011.

Collins Alan, Contemporary Security Studies, translated version published by UET Press, Tirana, 2011.

Hysa Mahmut, University of Tetovo, Ohrid Agreement Census-Omnium, published in the "Implementation of the Ohrid Framework Agreement", Ink International, Skopje 2003.

Ibrahimi Mustafa, South East European University-Tetovo. Solving the problem of language in multiethnic states, What's the closest that language, "Implementation of the Ohrid Framework Agreement", Ink International, Skopje 2003.

Munishi Shkumbini, Equality of languages in Kosovo and European perspective, International Balkan Congress, Pristina, 11 to 16 May 2009.

Ndreca Mark, Western Balkans in the context of challenges and (dis)integration, Publishing House "Geer" Tirana 2010.

Zendeli Fadil, South East European University, the Ohrid Framework Agreement and the equality of languages in the Republic of Macedonia, published in the publication "Implementation of the Ohrid Framework Agreement", The Ink International, Skopje 2003. 
